\title{
Sloping Land Use Affects Soil Moisture and Temperature in the Loess Hilly Region of China
}

\author{
Min Tang ${ }^{1}$, Xiaodong Gao ${ }^{2,3}$, Chao Zhang ${ }^{1, *}$, Xining Zhao ${ }^{2,3, *}$ and Pute $\mathrm{Wu}^{2,3}$ \\ 1 College of Hydraulic Science and Engineering, Yangzhou University, Yangzhou 225009, China; \\ tangmin0511@126.com \\ 2 Institute of Water-saving Agriculture in Arid Areas of China, Northwest Agriculture and Forestry University, \\ Yangling 712100, China; gao_xiaodong@nwafu.edu.cn (X.G.); gjzwpt63@163.com (P.W.) \\ 3 Institute of Soil and Water Conservation, Northwest Agriculture and Forestry University, \\ Yangling 712100, China \\ * Correspondence: zhangc1700@yzu.edu.cn (C.Z.); zxn@nwsuaf.edu.cn (X.Z.)
}

Received: 22 April 2020; Accepted: 28 May 2020; Published: 29 May 2020

check for updates

\begin{abstract}
Revealing the characteristics of soil moisture and temperature under typical sloping land uses in the loess hilly region is of great significance for the efficient and sustainable use of sloping land resources. In this study, the soil moisture content in the 0-160 cm soil layer and the soil temperature in the 0-100 cm soil layer under soybean sloping field, maize terraced field, jujube orchard, and grassland were continuously observed during the 2014 and 2015 growing seasons (May to October). Traditional statistical analysis and wavelet fractal dimension method were used to study the characteristics and complexity of soil moisture and temperature changes under different sloping land uses. The main findings are as follows: (1) Maize terraced field obtained high soil moisture content in the 0-160 $\mathrm{cm}$ soil layer, showing the outstanding effect of soil moisture conservation, especially in the drought growing season. Maize terraced field minimized the changing amplitude $\left(K_{\mathrm{a}}\right)$, variation degree $\left(C_{v}\right)$, and active layer of soil moisture in the $0-160 \mathrm{~cm}$ soil layer and the $K_{\mathrm{a}}$ and $C_{v}$ of soil temperature in the $0-100 \mathrm{~cm}$ soil layer. The maize terraced field had the minimum fractal dimensions of soil moisture and temperature both in normal precipitation and drought growing seasons, indicating that the maize terraced field minimized the complexity of soil moisture and temperature changes. (2) The jujube orchard obtained the minimum soil moisture content in the $0-160 \mathrm{~cm}$ soil layer, and greatly increased the $K_{\mathrm{a}}, C_{v}$, and active layer of soil moisture both in normal precipitation and drought growing seasons. The jujube orchard obtained the maximum soil temperature in the $0-100 \mathrm{~cm}$ soil layer, and greatly increased the $K_{\mathrm{a}}$ and $C_{v}$ of soil temperature. The jujube orchard also had the maximum fractal dimensions of soil moisture and temperature, indicating that soil moisture and temperature changes in jujube orchard were the most complex. (3) Compared to jujube orchard, soybean sloping field and grassland increased soil moisture content, reduced the $K_{\mathrm{a}}$ and $C_{v}$ of soil moisture and temperature, and weakened the complexity of soil moisture and temperature changes. (4) The analysis results of the complexity of soil moisture and temperature changes under the experimental sloping land uses based on the wavelet fractal dimension method were consistent with the traditional statistical analysis results, indicating that it is feasible to evaluate the complexity of soil moisture and temperature changes under the typical sloping land uses in the loess hilly region by using wavelet fractal dimension method. In summary, terraced fields were conducive to improving soil moisture content and maintaining the stability of soil moisture and temperature. It is recommended that the project of changing sloping fields into terraced fields should be popularized in the loess hilly region to effectively utilize limited natural precipitation. In order to prevent the jujube orchard from degenerating and dying due to long-term drought and water shortage, effective water management measures need to be taken to achieve the sustainable development of dry farming jujube orchard.
\end{abstract}

Keywords: sloping land use; soil moisture; soil temperature; loess hilly region; wavelet fractal dimension 


\section{Introduction}

Soil hydrothermal conditions are the key factors affecting vegetation growth [1,2]. Soil moisture and soil temperature are two important indicators reflecting soil hydrothermal characteristics. Most of the water needed for plants is obtained by roots absorbing soil moisture. Soil moisture not only significantly affects plant physiological activities such as photosynthesis, water metabolism, and nutrient transport, but also affects the biomass, morphological characteristics, and physiological activities of plant root [3-5]. In arid and semi-arid regions, soil moisture is the main limiting factor affecting plant growth and vegetation restoration [6]. Drought climate, sparse precipitation, and strong soil evaporation lead to lack of surface water resources in the loess hilly region of China. In addition, groundwater is buried deeply and difficult to be absorbed by plants. The above factors make soil moisture almost the only available water resource for the vegetation in the loess hilly dry farming region. Therefore, soil moisture has become a core factor restricting regional economic development and ecological environment restoration [7]. Soil temperature not only affects the physiological activities of the aboveground parts of plants, but also directly affects the growth, respiration, and nutrient uptake of underground roots [8,9]. The loess hilly region is dominated by loessial soil, which is characterized by loose and porous soil structure, undeveloped soil profile, severe soil erosion, low soil fertility, and good water permeability [10]. In addition, the loessial soil has a light color and a low specific heat, resulting in a relatively low and widely varying soil temperature [11]. In summary, studying soil moisture and temperature changes in the loess hilly region helps in taking timely soil management measures to preserve soil moisture and regulate soil temperature to ensure the normal growth of plants, which is of great significance for guiding regional vegetation management and ecological restoration.

In arid and semi-arid regions, land use is an important factor affecting soil moisture and temperature changes [12,13]. Soil moisture dynamics are affected by precipitation and evapotranspiration, and land use affects soil moisture distribution by affecting precipitation infiltration and evapotranspiration, thereby controlling soil moisture variability in local areas [14,15]. Land use also significantly affects soil temperature. The difference in topography, the presence or absence of vegetation, the difference in vegetation types, and the level of surface coverage indirectly affect the temperature changes in near-surface air and soil [16]. To date, a large number of theoretical and experimental studies have been carried out on soil moisture and temperature under different land uses. Ma et al. [17] studied the soil hydrothermal effects of typical land use patterns (i.e., abandoned sloping land, Caragana korshinskii Kom. shrubland, and soybean sloping farmland) after five years of returning farmland in the Loess Plateau of south Ningxia. Gao and Shao [18] analyzed the dynamic changes in soil moisture and temperature under different land use patterns (i.e., alfalfa land and bare land) during once rainfall at the time of alternation of drying and wetting in arid loess region through positioning monitoring and statistical methods. Yu et al. [19] investigated and compared the differences in soil moisture under three typical land use patterns (i.e., forest land, native grassland, and farmland) in a small watershed of the semi-arid Loess Plateau. In addition, the authors also discussed the spatial variation in soil moisture in the $0-100 \mathrm{~cm}$ soil layer during the dry and wet periods. Savva et al. [20] studied the effects of land use and vegetation cover (forest and grassland) on soil temperature in urban ecosystems. However, previous studies have mostly used traditional statistical analysis methods, and mainly focused on the qualitative description of soil moisture and temperature changes, which have the shortcomings of simple research methods and lack of innovation. In addition, there are few studies on the complexity of soil moisture and temperature changes in different sloping land uses in the loess hilly region. In fact, due to the combined effects of meteorological factors, vegetation cover, and topography, soil moisture and temperature changes present a series of unique complexities. In particular, climate anomalies and the adjustment of land use structure in the loess hilly region in recent years have resulted in significant changes in the complexity of soil moisture and temperature variation. How to further understand the complexity of soil moisture and temperature under different sloping land uses is an important research topic in soil science, and an important prerequisite for realizing effective and sustainable utilization of sloping land resources in the loess hilly region. 
The fractal theory was first proposed by Mandelbrot [21]. Its basic feature is to describe the complexity of objective things with fractal mathematical methods, and the fractal dimension is an indicator for quantitatively characterizing the complexity. The key to the fractal theory lies in the calculation of the fractal dimension. Although there are many methods that can be used to extract the fractal dimension, the different methods have different focuses, which makes the calculated fractal dimension quite different and unstable. Until the birth of wavelet analysis, the above problems can be solved. Wavelet analysis has the function of time-frequency multi-resolution, and there is statistical self-similarity between the large-scale and small-scale wavelet transforms, so it can be used to easily extract the spectrum index and further estimate the fractal dimension. Fu et al. [22] used fractal theory based on wavelet transform to quantitatively study the effects of different snow cover on the spatial variability in soil moisture and temperature. The results show that the fractal theory based on wavelet transform is accurate and reliable in studying the complexity of soil moisture and temperature under snow cover during the freezing-thawing period. Luan et al. [23] used the wavelet fractal dimension method to clarify the different distributions of regional rainfall complexity in different periods in parts of Hebei Province in the Qingzhang River Watershed of Haihe River Basin, China, and the analysis results are basically consistent with the relevant research results. In summary, the fractal dimension based on wavelet analysis is effective and reasonable, and can be used to characterize the complexity of the change in the research object.

This study took four typical sloping land uses (i.e., soybean sloping field, maize terraced field, jujube orchard, and grassland) in the loess hilly region as the research object. The research contents are as follows: (1) the variation characteristics of soil moisture and temperature under different sloping land uses in normal precipitation and drought growing seasons were analyzed based on traditional statistics; (2) the complexity of soil moisture and temperature in each sloping land use was evaluated based on wavelet fractal dimension method; and (3) the commonalities and differences between the results obtained by traditional statistics and wavelet fractal dimension method were compared. This study explored the feasibility of using a wavelet fractal dimension method to evaluate the complexity of soil moisture and temperature changes under typical sloping land uses in the loess hilly region, and proposed some suggestions for improving sloping land use, in order to provide a scientific basis for the optimization of sloping land use and the sustainable utilization of sloping land resources in the loess hilly region and other arid and semi-arid areas.

\section{Materials and Methods}

\subsection{Site Description}

The experiment was conducted in the Yuanzegou catchment $\left(37^{\circ} 13^{\prime} 38^{\prime \prime}-37^{\circ} 14^{\prime} 22^{\prime \prime} \mathrm{N}, 110^{\circ} 21^{\prime} 10^{\prime \prime}-\right.$ $110^{\circ} 21^{\prime} 32^{\prime \prime}$ E, 865-1105 m above sea level; Figure 1a), Qingjian County, Yulin City, in the loess hilly region of China during the growing season (May to October) in 2014 and 2015. The soil erosion in this catchment is serious, and the gullies are crisscrossed. The study area is located in a warm temperate continental monsoon semi-arid climate zone with an average annual precipitation of $497 \mathrm{~mm}$ and $70 \%$ of precipitation occurring from June to September (Figure 2a). The mean annual air temperature is $9.6^{\circ} \mathrm{C}$, with a monthly average maximum air temperature of $30.1^{\circ} \mathrm{C}$ in July and a monthly average minimum air temperature of $-12.2^{\circ} \mathrm{C}$ in January (Figure 2a), and the temperature difference in daytime and night and the seasonal variation of air temperature are both great. The annual sunshine duration in the study area is $2720 \mathrm{~h}$, and the frost-free period is 156 days. The average annual rainfall from May to October in the study area is $430.2 \mathrm{~mm}$ (Figure 2a). The total rainfall during the 2014 growing season was $377.4 \mathrm{~mm}$ (Figure 2b); compared to the average annual rainfall during the same period, the reduction was less than $10 \%$, so the 2014 growing season was a normal precipitation growing season [24]. The total rainfall in the 2015 growing season was only $289.2 \mathrm{~mm}$ (Figure 2b), and as the reduction of rainfall exceeded 10\%, the 2015 growing season was considered a drought growing season [24]. The soil in the study area is loessial soil, which is a typical silty 
loam with loose texture and strong infiltration capacity. The field capacity and wilting moisture are $25 \%$ (volume) and 7\% (volume), respectively.

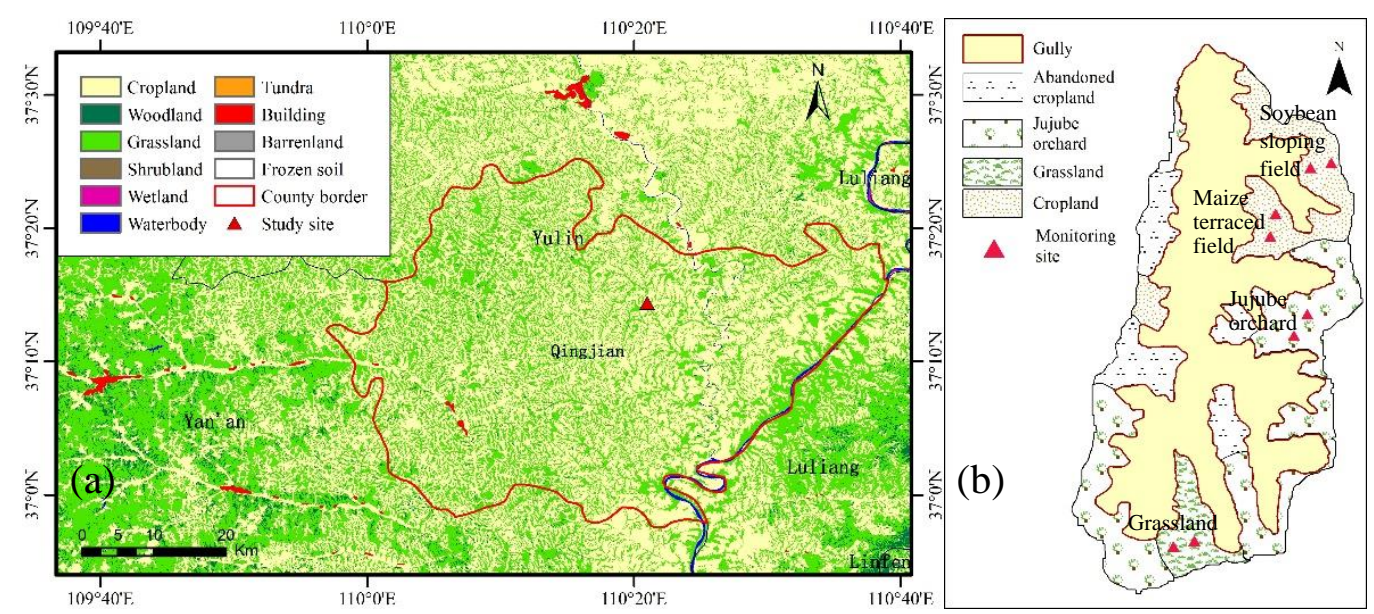

Figure 1. Land use distribution (a) and the locations of the four experimental sloping land uses (b) in the study area. The land use data were obtained from the global land cover with $30 \mathrm{~m}$ resolution (GlobalLand30) for the year 2010, produced by National Geomatics Center of China (http://www.globallandcover.com/GLC30Download/index.aspx).

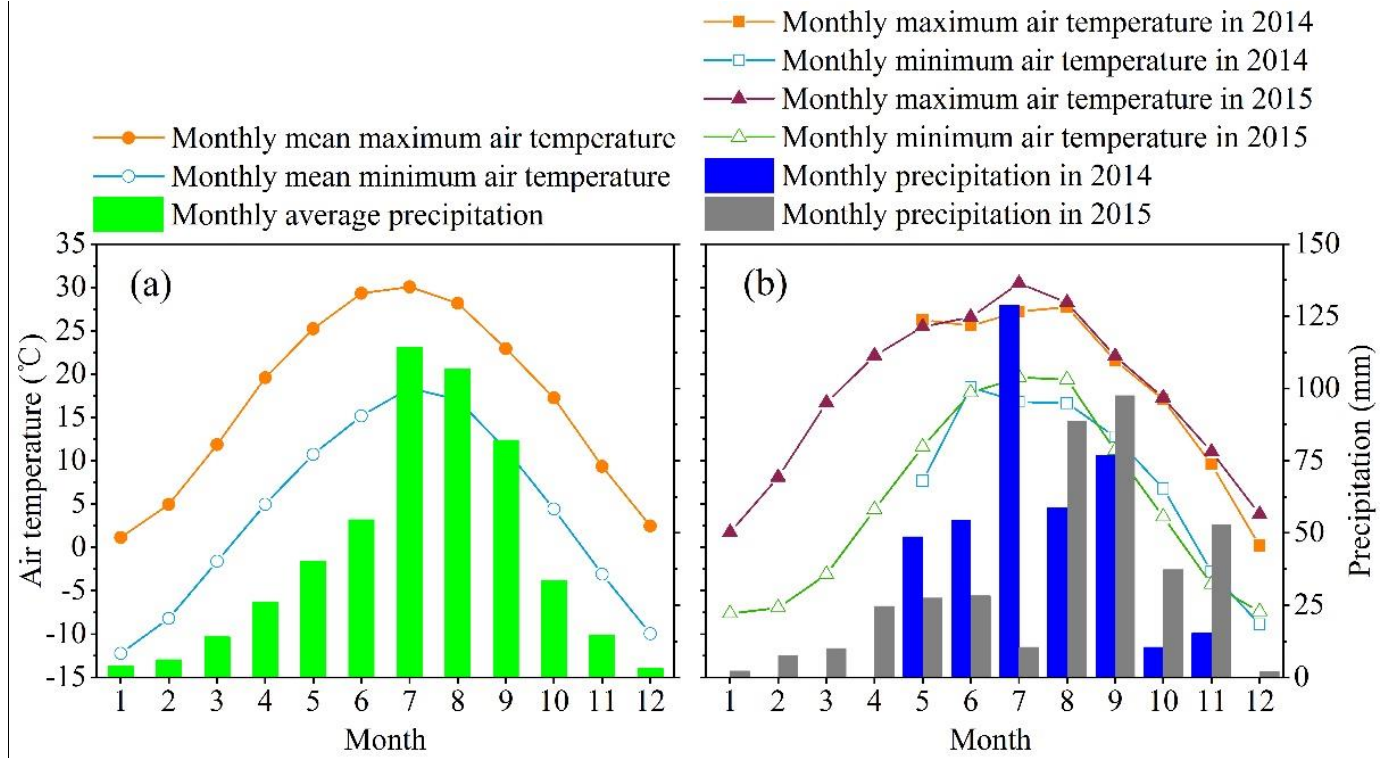

Figure 2. Climate background (a) and monthly precipitation and air temperature in 2014 and 2015 (b) in the study area. The monthly mean air temperature and precipitation data in the study area were obtained from the statistical data released by National Meteorological Center of CMA (http://www.nmc.cn/publish/forecast/ASN/qingiian.html). Since the AR-5 automatic weather station for monitoring meteorological factors in the study area was installed in late April 2014, the meteorological data was calculated from May 2014.

\subsection{Experimental Design}

The study area is covered by large areas of cultivated land, grassland, and scattered woodland (Figure 1a). In view of this, soybean sloping field, maize terraced field, jujube orchard, and grassland with similar slope aspects and gradients were selected as experimental land uses (Figure 1b). Since there were few sloping lands with the same characteristics (vegetation, aspect, gradient, etc.) in the study area, only one representative sloping land was selected to characterize a land use. The four experimental land uses were not irrigated during the experiment, and the management measures were in accordance with the local 
conditions. The basic information for the experimental land uses is shown in Table 1. The basic soil physical properties and nutrient contents under four experimental sloping land uses are shown in Table 2.

Table 1. General information of experimental land uses.

\begin{tabular}{|c|c|c|c|}
\hline Sloping Land Use & Slope Gradient $\left({ }^{\circ}\right)$ & Slope Aspect & Description \\
\hline Soybean sloping field & 18 & Shady slope & $\begin{array}{l}\text { The cultivation period is over } 30 \text { years, } \\
\text { and the cropping system is one crop per } \\
\text { year. Soybean (Glycine max (Linn.) Merr.) } \\
\text { was sown in late April with a planting } \\
\text { density of } 19.5 \times 10^{4} \text { plants per hectare and } \\
\text { harvested in early October. Fertilizer was } \\
\text { rarely applied and weeds were removed } \\
\text { regularly during the experiment. }\end{array}$ \\
\hline Maize terraced field & 20 & Shady slope & $\begin{array}{l}\text { The terraced field has been cultivated for } \\
\text { many years, and the cropping system is one } \\
\text { crop a year. Maize (Zea mays L.) was sown } \\
\text { in early May with a planting density of } 9 \times \\
10^{4} \text { plants per hectare and harvested in } \\
\text { early October. Fertilizer was seldom } \\
\text { applied and regular weeding was done. }\end{array}$ \\
\hline Jujube orchard & 20 & Shady slope & $\begin{array}{l}\text { The variety of jujube (Ziziphus jujuba Mill.) } \\
\text { is Lizao, which was planted in } 2003 \text { with } \\
\text { a plant spacing of } 2 \mathrm{~m} \text { and a row spacing of } \\
3 \mathrm{~m} \text {. During the experiment, jujube trees } \\
\text { were in full bearing period. A small amount } \\
\text { of farm manure and urea were applied at } \\
\text { the beginning of each year. Weeds in the } \\
\text { orchard were removed regularly. }\end{array}$ \\
\hline Grassland & 17 & Shady slope & $\begin{array}{l}\text { Grassland is naturally restored from slope } \\
\text { farmland for more than } 30 \text { years. } \\
\text { The eugenic vegetation is Artemisia gmelinii, } \\
\text { and the associated vegetation is Lespedeza } \\
\text { davurica, Bothriochloa ischaemum, etc. }\end{array}$ \\
\hline
\end{tabular}


Table 2. Physical properties and nutrient content of experimental land uses. The sampling date was September 5, 2014. Date are mean \pm SD, $n=3$. Soil particle composition: Sand $\%$ (0.02-2 mm), Silt $\%(0.002-0.02 \mathrm{~mm})$, and Clay\% $(<0.002 \mathrm{~mm})$.

\begin{tabular}{|c|c|c|c|c|c|c|c|c|c|}
\hline \multirow{2}{*}{ Sloping Land Use } & \multirow{2}{*}{$\begin{array}{l}\text { Soil Layer } \\
\text { (cm) }\end{array}$} & \multirow{2}{*}{$\begin{array}{l}\text { Bulk Density } \\
\left(\mathrm{g} \cdot \mathrm{cm}^{-3}\right)\end{array}$} & \multicolumn{3}{|c|}{ Soil Texture } & \multirow{2}{*}{$\begin{array}{l}\text { Soil Porosity } \\
(\%)\end{array}$} & \multirow{2}{*}{$\begin{array}{c}\text { Saturated Hydraulic } \\
\text { Conductivity } \\
\left(\mathrm{cm} \cdot \mathrm{d}^{-1}\right)\end{array}$} & \multirow{2}{*}{$\begin{array}{c}\text { Organic Matter } \\
\left(\mathrm{g} \cdot \mathrm{kg}^{-1}\right)\end{array}$} & \multirow{2}{*}{$\begin{array}{c}\text { Total N } \\
\left(\mathrm{g} \cdot \mathrm{kg}^{-1}\right)\end{array}$} \\
\hline & & & Sand (\%) & Silt (\%) & Clay (\%) & & & & \\
\hline \multirow{3}{*}{$\begin{array}{c}\text { Soybean } \\
\text { sloping field }\end{array}$} & $0-20$ & $1.17 \pm 0.15$ & $21.0 \pm 5.6$ & $63.0 \pm 3.7$ & $16.0 \pm 3.9$ & $58.9 \pm 5.6$ & \multirow{3}{*}{$74.2 \pm 20.6$} & $3.34 \pm 0.24$ & $0.29 \pm 0.02$ \\
\hline & $20-40$ & $1.29 \pm 0.11$ & $19.5 \pm 5.4$ & $63.4 \pm 2.4$ & $17.0 \pm 4.5$ & $54.3 \pm 3.7$ & & $2.66 \pm 0.31$ & $0.22 \pm 0.04$ \\
\hline & $40-60$ & - & $19.9 \pm 3.9$ & $65.0 \pm 1.9$ & $15.1 \pm 3.2$ & - & & $2.52 \pm 0.38$ & $0.20 \pm 0.02$ \\
\hline \multirow{3}{*}{ Maize terraced field } & $0-20$ & $1.26 \pm 0.11$ & $17.7 \pm 1.9$ & $63.8 \pm 2.3$ & $18.5 \pm 2.9$ & $55.1 \pm 4.2$ & \multirow{3}{*}{$55.6 \pm 10.4$} & $4.24 \pm 0.37$ & $0.30 \pm 0.03$ \\
\hline & $20-40$ & $1.36 \pm 0.07$ & $16.6 \pm 3.9$ & $64.9 \pm 1.7$ & $18.6 \pm 4.1$ & $52.5 \pm 2.7$ & & $2.98 \pm 0.33$ & $0.22 \pm 0.03$ \\
\hline & $40-60$ & - & $16.2 \pm 4.1$ & $63.3 \pm 1.1$ & $20.5 \pm 4.2$ & - & & $2.74 \pm 0.42$ & $0.20 \pm 0.03$ \\
\hline \multirow{3}{*}{ Jujube orchard } & $0-20$ & $1.31 \pm 0.12$ & $23.7 \pm 4.0$ & $62.6 \pm 1.9$ & $13.7 \pm 2.4$ & $51.7 \pm 4.5$ & \multirow{3}{*}{$36.6 \pm 9.6$} & $3.64 \pm 0.85$ & $0.31 \pm 0.06$ \\
\hline & $20-40$ & $1.41 \pm 0.10$ & $21.6 \pm 3.4$ & $64.0 \pm 1.9$ & $14.4 \pm 2.7$ & $52.1 \pm 3.8$ & & $2.76 \pm 0.89$ & $0.26 \pm 0.05$ \\
\hline & $40-60$ & - & $20.7 \pm 2.2$ & $64.2 \pm 1.2$ & $15.1 \pm 2.5$ & - & & $2.60 \pm 0.66$ & $0.27 \pm 0.05$ \\
\hline \multirow{3}{*}{ Grassland } & $0-20$ & $1.28 \pm 0.09$ & $17.3 \pm 2.8$ & $63.6 \pm 1.3$ & $19.1 \pm 3.4$ & $54.0 \pm 3.4$ & \multirow{3}{*}{$35.3 \pm 8.3$} & $5.12 \pm 0.79$ & $0.34 \pm 0.04$ \\
\hline & $20-40$ & $1.28 \pm 0.04$ & $15.1 \pm 1.7$ & $62.9 \pm 1.6$ & $22.0 \pm 0.7$ & $52.1 \pm 1.5$ & & $4.43 \pm 0.28$ & $0.28 \pm 0.04$ \\
\hline & $40-60$ & - & $14.9 \pm 3.7$ & $63.3 \pm 1.3$ & $21.8 \pm 3.8$ & - & & $4.23 \pm 0.36$ & $0.28 \pm 0.06$ \\
\hline
\end{tabular}




\subsection{Soil Moisture and Temperature Measurement}

Two sets of soil moisture and temperature automatic monitoring devices were installed in the middle of each experimental land use along the same contour at a distance of $10 \mathrm{~m}$ (Figure 1b). The monitoring devices for maize terraced field, jujube orchard, and grassland were installed in late April 2014. Due to the delay in delivery, the installation of devices for soybean sloping field lagged by one month. The observation points for soybean sloping field and maize terraced field were located between crop rows, and the monitoring probes for jujube orchard were buried $30 \mathrm{~cm}$ away from the trunk.

The soil volumetric moisture content and soil temperature were measured by the EC-5 soil moisture sensors (Decagon Devices, Pullman, WA, USA) and the RR-7110 soil temperature sensors (Rainroot Scientific Ltd., Peking), respectively. The soil moisture sensors had an accuracy of $\pm 3 \%$ VWC (volumetric water content), a resolution of $0.25 \%$ VWC, and a buried depth of 10, 20, 60, 100, and $160 \mathrm{~cm}$, respectively. The measurement accuracy and resolution of soil temperature sensors were \pm 0.2 and $0.02{ }^{\circ} \mathrm{C}$, and the buried depth was $10,20,40,60$, and $100 \mathrm{~cm}$, respectively. Soil moisture and temperature were measured during the vegetation growing season (i.e., May to October) in 2014 and 2015. The measurement frequency was $2 \mathrm{~min}$, and the data were recorded every $10 \mathrm{~min}$. For the same sloping land use, the soil moisture at two monitoring points at the same depth was averaged to characterize the soil moisture at that depth. The same method was used for soil temperature. The precipitation and air temperature in the study area were collected by the AR- 5 automatic weather station (Avolon Scientific, Inc., Jersey City, NJ, USA) near the experimental land uses.

\subsection{Data Analysis}

In order to analyze the vertical characteristics of soil moisture and temperature under four typical experimental sloping land uses, the soil moisture profile was divided into 0-20, 20-60, and 60-160 cm, and the soil temperature profile was also divided into 0-20, 20-60, and 60-100 cm.

Extremum ratio $\left(K_{a}\right)$ and coefficient of variation $\left(C_{v}\right)$ were used to characterize soil moisture and temperature changes under different sloping land uses. $K_{a}$ was calculated using the following formula [25]

$$
K_{a}=\frac{x_{\max }}{x_{\min }}
$$

where $x_{\max }$ represents the maximum soil moisture and temperature, and $x_{\min }$ is the minimum soil moisture and temperature. The greater the $K_{a}$ is, the more dramatic the change in soil moisture and temperature is, and, vice versa, the more gradual the change is.

In statistics, $C_{v}$ is also called the "discrete coefficient", which is defined as the ratio of the standard deviation $(\sigma)$ to the mean $(\mu) . C_{v}$ was obtained according to Abdi [26] as follows

$$
C_{v}=\frac{\sigma}{\mu}
$$

$C_{v}$ can reflect the variability in soil moisture and temperature. The greater the $C_{v}$ is, the greater the variability in soil moisture and temperature is, and, vice versa, the less the variability is. According to $\mathrm{Yu}$ et al. [27], the degree of variation can be divided into strong variability $\left(C_{v} \geq 1.0\right)$, medium variability $\left(0.1<C_{v}<1.0\right)$, and weak variability $\left(C_{v} \leq 0.1\right)$.

The fractal dimension $(D)$ obtained by the combination of continuous wavelet transform and fractal theory was also used to evaluate the complexity of soil moisture and temperature changes under different sloping land uses. The greater the fractal dimension of soil moisture and temperature is, the more complex and severe the change is.

For the time sequence, the continuous wavelet transform formula is as follows [28]

$$
W_{f}(a, b)=\int_{-\infty}^{+\infty} f(t) \cdot \Psi_{a, b}(t) \cdot d t
$$


where $W_{f}(a, b)$ represents the wavelet transform coefficient, $a$ is the time scale factor, and $b$ is the time position factor. $\Psi_{a, b}(t)$ is a cluster of functions obtained by scaling and translating $\Psi(t)$, called continuous wavelet, with the following expression

$$
\Psi_{a, b}(t)=|a|^{-\frac{1}{2}} \Psi\left(\frac{t-b}{a}\right) a, b \in R, a \neq 0
$$

The equation of spectrum index $(\alpha)$ is derived from the perspective of energy. The energy spectrum $\left(\Gamma\left(a_{j}\right)\right)$ of $W_{f}(a, b)$ at $a_{j}$ scale was obtained according to Abry and Veitch [29]

$$
\Gamma\left(a_{j}\right)=\frac{1}{n} \sum_{b=1}^{n}\left|W_{f}\left(a_{j}, b\right)\right|^{2}
$$

According to the spectral characteristics of the statistical self-similar process

$$
\Gamma\left(a_{j}\right) \propto a_{j}^{\alpha}
$$

Equation (6) was substituted into Equation (5), and logarithms were conducted for both sides of the equation

$$
\lg \left[\frac{1}{n} \sum_{b=1}^{n}\left|W_{f}\left(a_{j}, b\right)\right|^{2}\right]=\alpha \lg a_{j}+c_{0}
$$

where $c_{0}$ is a constant, and Equation (7) is the spectrum derivation equation.

Self-similarity index $(H)$ was calculated using the following formula [22]

$$
H=\left\{\begin{array}{cc}
\frac{\alpha+1}{2} & -1<\alpha<1 \\
\frac{\alpha-1}{2} & 1<\alpha<3
\end{array}\right.
$$

The fractal dimension $(D)$ of the time sequence was calculated according to $D=2-H$ [30]. Combined with Equation (8), $D$ was further calculated as follows

$$
D=\left\{\begin{array}{cc}
\frac{3-\alpha}{2} & -1<\alpha<1 \\
\frac{5-\alpha}{2} & 1<\alpha<3
\end{array}\right.
$$

In summary, the basic steps of the wavelet fractal dimension method are as follows:

(1) Calculate the wavelet transform coefficients. Referring to the previous research, the db4 wavelet function in MATLAB R2015b (The Mathworks, Natick, MA, USA) was selected in this study, and the soil moisture and temperature sequences in different soil layers under four sloping land uses were decomposed using Equations (3) and (4) to obtain wavelet transform coefficients at different $a_{j}$ scales;

(2) Calculate the energy spectrum $\Gamma\left(a_{j}\right)$ of wavelet transform at different $a_{j}$ scales using Equation (5);

(3) Using $\lg a_{j}$ as the independent variable and $\lg \left[\Gamma\left(a_{j}\right)\right]$ as the dependent variable, the linear regression was performed by SPSS 20.0 (SPSS Inc., Chicago IL, USA). The slope of the fitted line was the spectrum index $\alpha$, and then the fractal dimension $(D)$ of the soil moisture and temperature sequence was obtained.

Statistical analysis was performed using Microsoft Excel 2013 (Microsoft, Redmond, WA, USA) and SPSS 20.0 software. The independent samples $t$-test was used to identify differences in soil moisture and temperature in the same soil layer under different sloping land uses. Differences were considered statistically significant when $p<0.05$. 


\section{Results}

\subsection{Soil Moisture Variation Characteristics under Different Sloping Land Uses}

\subsubsection{Temporal Variation in Soil Moisture}

During the 2014 and 2015 growing seasons, the soil moisture in 0-20 cm under four experimental land uses exhibited obvious seasonal changes, which increased or decreased with the presence or absence of rainfall, showing alternating peak-valley characteristics (Figure 3a). Especially after the torrential rain with the cumulative rainfall of $86.6 \mathrm{~mm}$ from July 8 to 9,2014 , the soil moisture in 0-20 cm under all experimental land uses reached the peak value, and then decreased rapidly. In the 2014 growing season, the average moisture content of $0-20 \mathrm{~cm}$ soil layer in maize terraced field was not significantly different from that in grassland, both of which were about $14.9 \%$, but they were significantly higher than that in soybean sloping field $(14.59 \%)$ and jujube orchard $(11.23 \%)(p<0.05)$. During the 2015 growing season, the rainfall decreased drastically, resulting in a decline in the soil moisture content in the 0-20 cm soil layer under the four experimental land uses. The average moisture content in 0-20 cm soil layer of maize terraced field decreased to $12.32 \%$, but it was $2.42 \%, 4.21 \%$, and $2.35 \%$ higher than that of soybean sloping field, jujube orchard, and grassland, respectively $(p<0.05)$. The variation in the standard deviation of soil moisture in 0-20 cm soil layer between four experimental land uses was opposite to that of soil moisture. The standard deviation decreased with the increase in rainfall and soil moisture content, whereas it increased with the decrease in rainfall and soil moisture content. The results showed that under drought conditions, soil moisture in $0-20 \mathrm{~cm}$ soil layer was dispersed greatly under four experimental land uses, and the dispersion increased with the increase in drought. With the supplement of effective rainfall, the difference of soil moisture in 0-20 cm soil layer under four experimental land uses was reduced.

As soil depth increased, soil moisture fluctuations decreased under all experimental land uses, indicating that soil moisture was less affected by rainfall. In the 2014 growing season, the soil moisture content of grassland in 20-60 cm and 60-160 cm soil layers was significantly higher than that of other three sloping land uses $(p<0.05$; Figure $3 b, c)$. In the 2015 growing season, the average moisture content of maize terraced field in $20-60 \mathrm{~cm}$ soil layer was $3.54 \%, 4.76 \%$, and $1.18 \%$ higher than that of soybean sloping field, jujube orchard, and grassland, respectively $(p<0.05)$, and the moisture content of maize terraced field in 60-160 cm soil layer was still higher than that of other sloping land uses ( $p<0.05$; Figure 3b,c). In the 2014 and 2015 growing seasons, the soil moisture content of jujube orchard in 20-60 cm soil layer was significantly lower than that of other three sloping land uses ( $p<0.05$; Figure 3b). During the growing season of 2014 and 2015, the standard deviation in soil moisture in 20-60 cm soil layer between the four experimental land uses was relatively high, reaching an average of $2.55 \%$ and $2.33 \%$, respectively (Figure $3 \mathrm{~b}$ ). This may be due to the difference in root distribution in the $20-60 \mathrm{~cm}$ soil layer among the four sloping land uses, which causes the difference in root water absorption, and further leads to the great difference in soil moisture content in 20-60 cm soil layer. The standard deviation of soil moisture between experimental land uses in the 60-160 cm soil layer remained stable, and did not change significantly with rainfall or drought, and was significantly lower than that in the $0-20 \mathrm{~cm}$ and $20-60 \mathrm{~cm}$ soil layers, indicating that the soil moisture in the 60-160 cm soil layer was less affected by root water absorption (Figure 3c). 


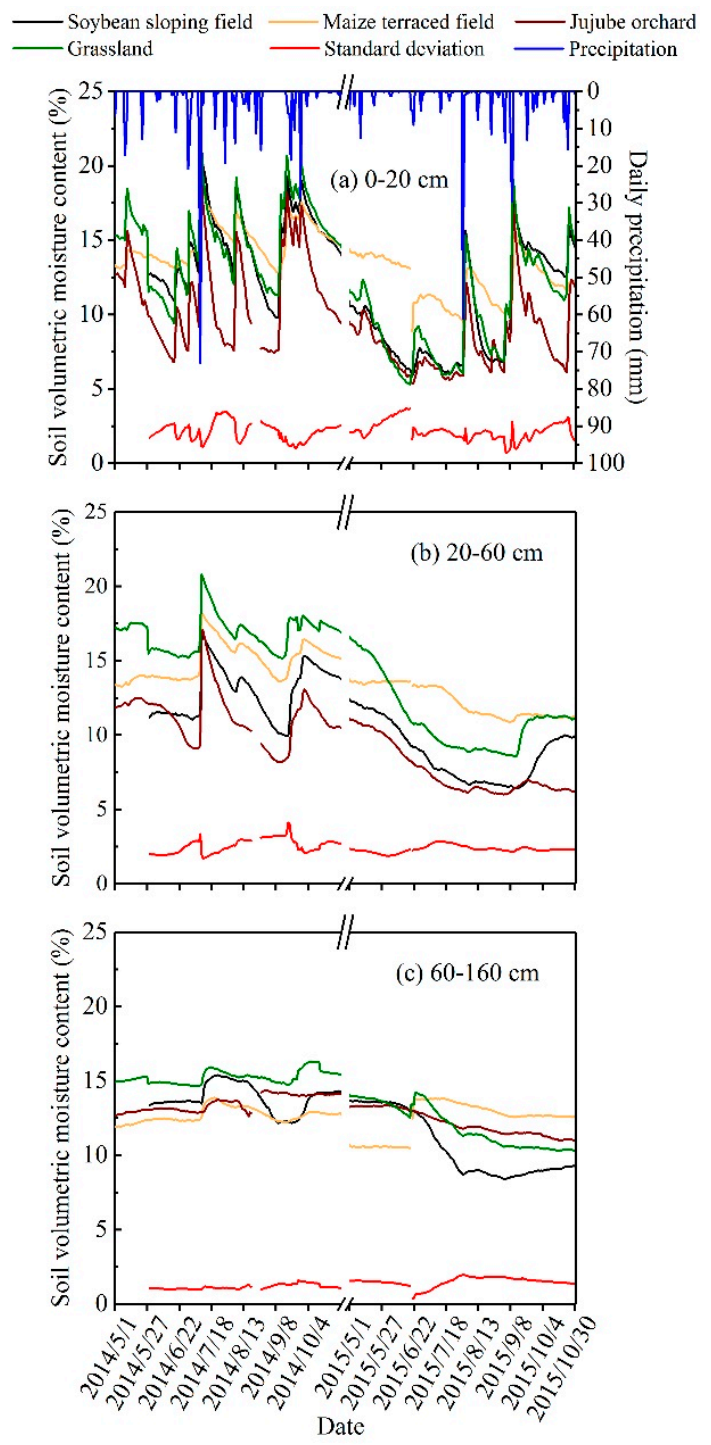

Figure 3. Dynamic changes of daily average soil moisture content in (a) $0-20 \mathrm{~cm}$, (b) $20-60 \mathrm{~cm}$, and (c) 60-160 cm soil layers and soil moisture standard deviation under different sloping land uses in 2014 and 2015 growing seasons. Due to the late installation of monitoring devices for soybean sloping field, soil moisture and temperature were collected from May 29, 2014. The standard deviation refers to the mean square error of daily average soil moisture content between soybean sloping field, maize terraced field, jujube orchard, and grassland, which can reflect the dispersion and difference in daily average soil moisture content between the four sloping land uses.

The comprehensive analysis of the soil moisture in the $0-160 \mathrm{~cm}$ soil layer under the four experimental sloping land uses revealed that there was a significant difference in the soil moisture in the 2014 growing season $(p<0.05)$. Grassland obtained the maximum average soil moisture content $(15.68 \%)$, followed by maize terraced field $(14.16 \%)$; the average soil moisture content of soybean sloping field decreased slightly compared to maize terraced field, and the jujube orchard received the minimum average soil moisture content, only $12.00 \%$. In the 2015 growing season, maize terraced field had the maximum average soil moisture content (12.34\%), which was increased by $2.58 \%, 3.07 \%$, and $1.32 \%$ compared to soybean sloping field, jujube orchard, and grassland $(p<0.05)$. 


\subsubsection{Vertical Variation of Soil Moisture}

In the 2014 and 2015 growing seasons, the $K_{a}$ and $C_{v}$ of soil moisture decreased with soil depth under the four experimental sloping land uses (Table 3). In the same soil layer, soil moisture changes were different due to differences in sloping land use. In the 2014 growing season, the $K_{a}$ of soil moisture in the 0-20 cm, 20-60 cm, and 60-160 cm soil layers was the highest in the jujube orchard, followed by the soybean sloping field and the lowest in the maize terraced field. The $C_{v}$ of soil moisture also showed the same pattern. In the 2015 growing season, the $K_{a}$ of soil moisture in 0-20 cm and 20-60 cm layers of jujube orchard was the highest, followed by soybean sloping field, while it was relatively low in maize terraced field, which was similar to the pattern of $C_{v}$. The $K_{a}$ and $C_{v}$ of soil moisture in 60-160 cm soil layer of jujube orchard were higher than those of the other three sloping land uses. The above results showed that the jujube orchard increased the $K_{a}$ and $C_{v}$ of soil moisture in $0-160 \mathrm{~cm}$ soil layer in both normal precipitation and drought growing seasons, while the maize terraced field reduced the $K_{a}$ and $C_{v}$ of soil moisture, and helped to maintain soil moisture stability.

Table 3. Statistical analysis of soil moisture changes in profile under different sloping land uses.

\begin{tabular}{|c|c|c|c|c|c|c|}
\hline \multirow{2}{*}{$\begin{array}{l}\text { Experimental } \\
\text { Year }\end{array}$} & \multirow{2}{*}{$\begin{array}{l}\text { Soil Layer } \\
\text { (cm) }\end{array}$} & \multirow{2}{*}{$\begin{array}{c}\text { Variation } \\
\text { Eigenvalue }\end{array}$} & \multicolumn{4}{|c|}{ Sloping Land Use } \\
\hline & & & $\begin{array}{c}\text { Soybean } \\
\text { Sloping Field }\end{array}$ & $\begin{array}{c}\text { Maize } \\
\text { Terraced Field }\end{array}$ & $\begin{array}{l}\text { Jujube } \\
\text { Orchard }\end{array}$ & Grassland \\
\hline \multirow{6}{*}{2014} & \multirow{2}{*}{$0-20$} & $K_{\mathrm{a}}$ & 2.325 & 1.486 & 2.795 & 2.151 \\
\hline & & $C_{v}$ & 0.175 & 0.094 & 0.267 & 0.177 \\
\hline & \multirow{2}{*}{$20-60$} & $K_{\mathrm{a}}$ & 1.691 & 1.365 & 2.087 & 1.371 \\
\hline & & $C_{v}$ & 0.136 & 0.069 & 0.157 & 0.082 \\
\hline & \multirow{2}{*}{$60-160$} & $K_{\mathrm{a}}$ & 1.164 & 1.113 & 1.265 & 1.136 \\
\hline & & $C_{v}$ & 0.040 & 0.029 & 0.067 & 0.039 \\
\hline \multirow{6}{*}{2015} & \multirow{2}{*}{$0-20$} & $K_{\mathrm{a}}$ & 3.202 & 1.741 & 3.598 & 3.076 \\
\hline & & $C_{v}$ & 0.325 & 0.123 & 0.335 & 0.270 \\
\hline & \multirow{2}{*}{$20-60$} & $K_{\mathrm{a}}$ & 1.932 & 1.493 & 1.942 & 1.847 \\
\hline & & $C_{v}$ & 0.216 & 0.098 & 0.216 & 0.206 \\
\hline & \multirow{2}{*}{$60-160$} & $K_{\mathrm{a}}$ & 1.217 & 1.260 & 1.628 & 1.483 \\
\hline & & $C_{v}$ & 0.067 & 0.086 & 0.196 & 0.118 \\
\hline
\end{tabular}

The continuous soil layer with $C_{v}$ of soil moisture higher than 0.1 in each soil layer was defined as a soil moisture active layer. Taking the soybean sloping field in the 2014 growing season as an example, the $C_{v}$ of $0-20 \mathrm{~cm}, 20-60 \mathrm{~cm}$, and $60-160 \mathrm{~cm}$ soil layers were $0.175,0.136$, and 0.040 , respectively (Table 3). The $C_{v}$ of each soil layer in $0-60 \mathrm{~cm}$ was higher than 0.1 , so the soil moisture active layer of soybean sloping field was the $0-60 \mathrm{~cm}$ soil layer. The soil moisture active layer of other sloping land uses was divided by the same method. In the 2014 growing season, the soil moisture active layers of jujube orchard and grassland were $0-60 \mathrm{~cm}$ and $0-20 \mathrm{~cm}$ soil layers, respectively. The $C_{v}$ of maize terraced field in each soil layer of $0-160 \mathrm{~cm}$ was less than 0.1 , indicating that the soil moisture was relatively stable. In the 2015 growing season with rare rainfall, the soil moisture active layers of jujube orchard and grassland moved down to $160 \mathrm{~cm}$, while the soil moisture of maize terraced field was only active in the $0-20 \mathrm{~cm}$ soil layer, and the soil moisture was relatively stable in the $20-160 \mathrm{~cm}$ soil layer.

\subsection{Characteristics of Soil Temperature Change under Different Sloping Land Uses}

\subsubsection{Seasonal Variation Characteristics of Soil Temperature}

During the growing season of 2014 and 2015, the soil temperature of 0-20 cm, 20-60 cm, and 60-100 cm layers under four experimental sloping land uses presented a single-peak curve, which was consistent with the seasonal variation in air temperature (Figure 4). In the early growing season, the temperature of all soil layers increased with the air temperature, and reached its peak in early August. Thereafter, the air temperature dropped, and the temperature of each soil layer 
also decreased. The change in soil temperature lagged behind that of air temperature, and with the deepening of soil depth, the time for soil temperature to reach its peak became more lagging.

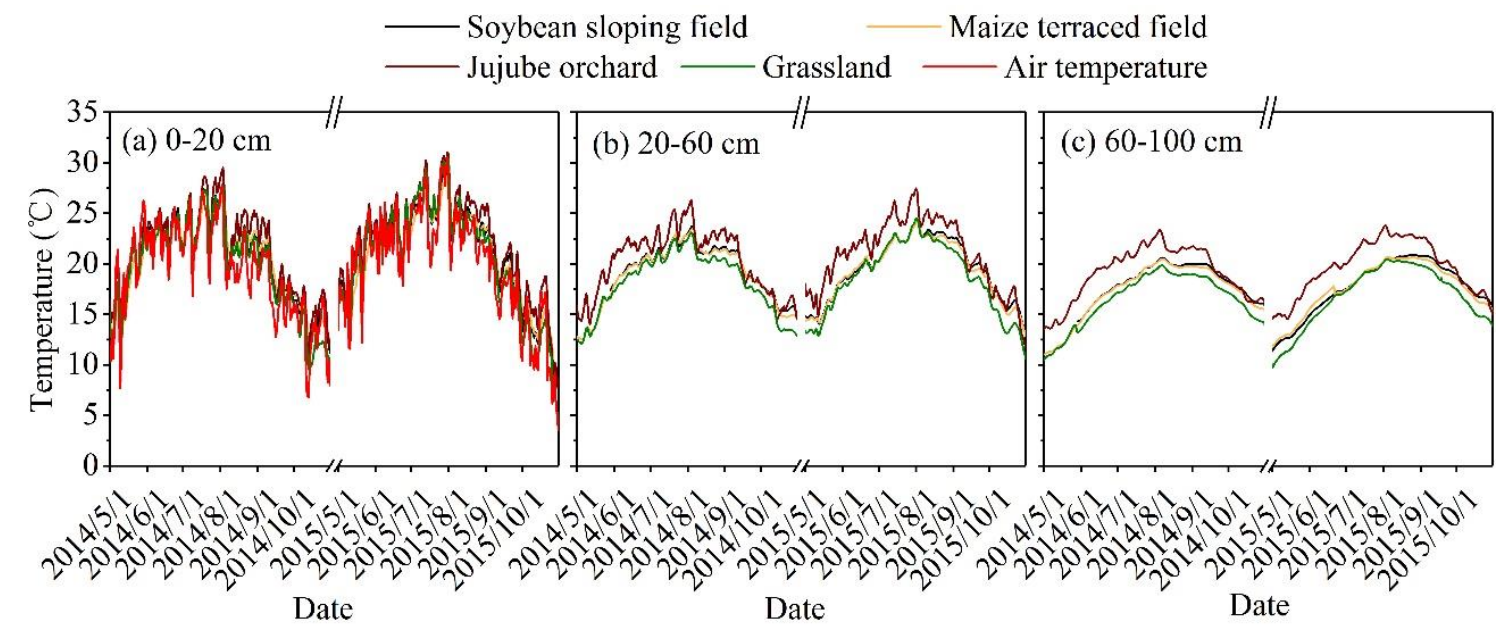

Figure 4. Dynamics of daily average soil temperature in (a) 0-20 cm, (b) $20-60 \mathrm{~cm}$, and (c) 60-100 cm soil layers under different sloping land uses during the 2014 and 2015 growing seasons.

Soil temperature fluctuated violently in 0-20 cm soil layer under four experimental sloping land uses, indicating that it was greatly affected by air temperature (Figure 4a). With the deepening of the soil layer, the daily average soil temperature gradually decreased for the same sloping land use, and the fluctuation range was also reduced. Taking the 2015 growing season as an example, the soil temperature of soybean sloping field, maize terraced field, jujube orchard, and grassland in $0-20 \mathrm{~cm}$ soil layer was $21.1,20.7,22.2$, and $20.6^{\circ} \mathrm{C}$, and the fluctuation range was $22.1,20.8,23.2$, and $25.3^{\circ} \mathrm{C}$, respectively (Figure 4a). To 60-100 $\mathrm{cm}$ soil layer, the soil temperature of soybean sloping field, maize terraced field, jujube orchard, and grassland decreased to $17.7,17.7,19.6$, and $16.8^{\circ} \mathrm{C}$, respectively, and the fluctuation range decreased to $9.6,9.0,9.3,10.8{ }^{\circ} \mathrm{C}$ in turn (Figure $4 \mathrm{c}$ ).

In the 2014 growing season, the temperature fluctuation range of $0-20 \mathrm{~cm}$ soil layer in maize terraced field was $14.8^{\circ} \mathrm{C}$, which was $2.3,3.5$, and $3.4^{\circ} \mathrm{C}$ lower than that in soybean sloping field, jujube orchard, and grassland, respectively (Figure 4a). In the $20-60 \mathrm{~cm}$ soil layer, the soil temperature fluctuations in maize terraced field, jujube orchard, and grassland were all above $11.0^{\circ} \mathrm{C}$, while it was only $8.7^{\circ} \mathrm{C}$ in soybean sloping field (Figure $4 \mathrm{~b}$ ). In the $60-100 \mathrm{~cm}$ soil layer, the soil temperature of soybean sloping field varied by $6.3{ }^{\circ} \mathrm{C}$, which was about $3.0^{\circ} \mathrm{C}$ lower than that of the other three sloping land uses (Figure 4c). In the 2015 growing season, the soil temperature of maize terraced field in 0-20 cm soil layer changed by $20.8{ }^{\circ} \mathrm{C}$, which was $1.3,2.5$, and $4.6^{\circ} \mathrm{C}$ lower than that of soybean sloping field, jujube orchard, and grassland, respectively (Figure 4a). In the 20-60 cm soil layer, the change range of soil temperature in maize terraced field and soybean sloping field was not significantly different, about $11.3^{\circ} \mathrm{C}$, which was 4.3 and $2.5^{\circ} \mathrm{C}$ lower than that in jujube orchard and grassland (Figure $4 \mathrm{~b}$ ). In the $60-100 \mathrm{~cm}$ soil layer, the change range of soil temperature in maize terraced field was only $9.0^{\circ} \mathrm{C}$, which was less than that in the other three sloping land uses (Figure 4c).

Based on the comprehensive analysis of soil temperature of $0-100 \mathrm{~cm}$ soil layer under four sloping land uses, it was found that the jujube orchard obtained the maximum average soil temperature, with 20.2 and $20.9^{\circ} \mathrm{C}$ in the 2014 and 2015 growing seasons, respectively. Jujube orchard also achieved the maximum fluctuation range of soil temperature with $12.3^{\circ} \mathrm{C}$ in the 2014 growing season and $15.8^{\circ} \mathrm{C}$ in the 2015 growing season. There was no significant difference in soil temperature between soybean sloping field and maize terraced field in the two growing seasons. Their soil temperatures were about 18.9 and $19.3^{\circ} \mathrm{C}$ in the 2014 and 2015 growing seasons, respectively. The grassland obtained the lowest soil temperature, which was significantly lower than that of other sloping land uses in two growing seasons $(p<0.05)$. Soybean sloping field had the minimum fluctuation range of soil temperature 
$\left(9.8^{\circ} \mathrm{C}\right)$ in the 2014 growing season. Maize terraced field got the minimum fluctuation range of soil temperature $\left(12.3^{\circ} \mathrm{C}\right)$ in the 2015 growing season.

\subsubsection{Vertical Variation of Soil Temperature}

Although the sloping land was utilized in different ways, the change in soil temperature in the vertical direction was consistent. With the increase in soil depth, the $K_{a}$ and $C_{v}$ of soil temperature decreased (Table 4). In the 2014 growing season, the $K_{a}$ and $C_{v}$ of soil temperature in 0-20 cm soil layer of jujube orchard were higher than those of other three sloping land uses, while the $K_{a}$ and $C_{v}$ of soil temperature in the maize terraced field were relatively small. In $20-60 \mathrm{~cm}$ and $60-100 \mathrm{~cm}$ soil layers, the $K_{a}$ of soil temperature in jujube orchard was the highest, followed by soybean sloping field, and it was the lowest in the maize terraced field. The $C_{v}$ of soil temperature under four experimental sloping land uses also showed the same trend. In the 2015 growing season, the $K_{a}$ of soil temperature in the $0-20 \mathrm{~cm}$ and $20-60 \mathrm{~cm}$ soil layers was the highest in the jujube orchard, followed by the soybean sloping field and the lowest in the maize terraced field, which was consistent with the $C_{v}$ of soil temperature. The $K_{a}$ and $C_{v}$ of soil temperature in $60-100 \mathrm{~cm}$ soil layer of jujube orchard were 2.120 and 0.175 , respectively, which were significantly higher than those in maize terraced field, grassland, and soybean sloping field. In summary, the jujube orchard obtained the maximum $K_{a}$ and $C_{v}$ of soil temperature in the $0-100 \mathrm{~cm}$ soil layer during normal precipitation and drought growing seasons, while the maize terraced field had low $K_{a}$ and $C_{v}$.

Table 4. Statistical analysis of soil temperature changes in profile under different sloping land uses.

\begin{tabular}{|c|c|c|c|c|c|c|}
\hline \multirow{2}{*}{$\begin{array}{c}\text { Experimental } \\
\text { Year }\end{array}$} & \multirow{2}{*}{$\begin{array}{l}\text { Soil Layer } \\
\text { (cm) }\end{array}$} & \multirow{2}{*}{$\begin{array}{c}\text { Variation } \\
\text { Eigenvalue }\end{array}$} & \multicolumn{4}{|c|}{ Sloping Land Use } \\
\hline & & & $\begin{array}{c}\text { Soybean } \\
\text { Sloping Field }\end{array}$ & $\begin{array}{c}\text { Maize } \\
\text { Terraced Field }\end{array}$ & $\begin{array}{l}\text { Jujube } \\
\text { Orchard }\end{array}$ & Grassland \\
\hline \multirow{6}{*}{2014} & \multirow{2}{*}{$0-20$} & $K_{\mathrm{a}}$ & 2.587 & 2.214 & 2.911 & 2.646 \\
\hline & & $C_{v}$ & 0.202 & 0.197 & 0.234 & 0.200 \\
\hline & \multirow{2}{*}{$20-60$} & $K_{\mathrm{a}}$ & 1.884 & 1.579 & 1.910 & 1.870 \\
\hline & & $C_{v}$ & 0.159 & 0.113 & 0.166 & 0.156 \\
\hline & \multirow{2}{*}{$60-100$} & $K_{\mathrm{a}}$ & 1.861 & 1.440 & 1.887 & 1.721 \\
\hline & & $C_{v}$ & 0.154 & 0.091 & 0.155 & 0.137 \\
\hline \multirow{6}{*}{2015} & \multirow{2}{*}{$0-20$} & $K_{\mathrm{a}}$ & 3.974 & 3.569 & 5.852 & 3.912 \\
\hline & & $C_{v}$ & 0.228 & 0.218 & 0.272 & 0.219 \\
\hline & \multirow{2}{*}{$20-60$} & $K_{\mathrm{a}}$ & 2.306 & 1.857 & 2.339 & 1.882 \\
\hline & & $C_{v}$ & 0.167 & 0.156 & 0.190 & 0.154 \\
\hline & \multirow{2}{*}{ 60-100 } & $K_{\mathrm{a}}$ & 1.636 & 1.843 & 2.120 & 1.770 \\
\hline & & $C_{v}$ & 0.135 & 0.152 & 0.175 & 0.141 \\
\hline
\end{tabular}

\subsection{Wavelet Fractal Dimension of Soil Moisture and Temperature}

In the 2014 and 2015 growing seasons, the determination coefficient $\left(R^{2}\right)$ of soil moisture and temperature in each soil layer under the four experimental sloping land uses were greater than 0.98 , and all reached the significance level $(p<0.05)$, indicating that the fitting effect of the spectrum derivation equation was good (Tables 5 and 6 ). The greater the fractal dimension of soil moisture and temperature is, the more complex the change is. In the section direction, the fractal dimension of soil moisture and temperature decreased with the deepening soil layer under different sloping land uses. Taking grassland as an example, in the 2014 growing season, the fractal dimensions of soil moisture in 0-20 cm, 20-60 cm, and 60-160 cm layers were 1.495, 1.460, and 1.412, respectively, and the fractal dimensions of soil temperature in $0-20 \mathrm{~cm}, 20-60 \mathrm{~cm}$, and $60-100 \mathrm{~cm}$ layers were $1.544,1.433$, and 1.308, respectively, which also showed similar patterns in the 2015 growing season. It demonstrates that the complexity of soil moisture and temperature changes decreased with the deepening soil layer. 
Table 5. Fractal dimension of soil moisture in 0-20 cm, 20-60 cm, and 60-160 cm soil layers under different sloping land uses during the 2014 and 2015 growing seasons.

\begin{tabular}{|c|c|c|c|c|c|c|}
\hline \multirow{2}{*}{$\begin{array}{l}\text { Experimental } \\
\text { Year }\end{array}$} & \multirow{2}{*}{$\begin{array}{l}\text { Soil Layer } \\
\text { (cm) }\end{array}$} & \multirow{2}{*}{$\begin{array}{c}\text { Fractal } \\
\text { Dimension }\end{array}$} & \multicolumn{4}{|c|}{ Sloping Land Use } \\
\hline & & & $\begin{array}{c}\text { Soybean } \\
\text { Sloping Field }\end{array}$ & $\begin{array}{c}\text { Maize } \\
\text { Terraced Field }\end{array}$ & $\begin{array}{l}\text { Jujube } \\
\text { Orchard }\end{array}$ & Grassland \\
\hline \multirow{9}{*}{2014} & \multirow{4}{*}{$0-20$} & $D$ & 1.497 & 1.489 & 1.507 & 1.495 \\
\hline & & $R^{2}$ & 0.999 & 0.999 & 0.999 & 0.999 \\
\hline & & $p$ & 0.000 & 0.000 & 0.000 & 0.000 \\
\hline & & $D$ & 1.496 & 1.433 & 1.500 & 1.460 \\
\hline & \multirow[t]{3}{*}{$20-60$} & $R^{2}$ & 1.000 & 0.999 & 1.000 & 0.999 \\
\hline & & $p$ & 0.000 & 0.000 & 0.000 & 0.000 \\
\hline & & $D$ & 1.434 & 1.345 & 1.480 & 1.412 \\
\hline & \multirow{2}{*}{$60-160$} & $R^{2}$ & 0.999 & 0.997 & 1.000 & 0.998 \\
\hline & & $p$ & 0.000 & 0.000 & 0.000 & 0.000 \\
\hline \multirow{9}{*}{2015} & \multirow{4}{*}{$0-20$} & $D$ & 1.431 & 1.429 & 1.526 & 1.431 \\
\hline & & $R^{2}$ & 0.996 & 0.998 & 0.999 & 0.995 \\
\hline & & $p$ & 0.000 & 0.000 & 0.000 & 0.000 \\
\hline & & $D$ & 1.412 & 1.383 & 1.432 & 1.384 \\
\hline & \multirow{3}{*}{$20-60$} & $R^{2}$ & 0.999 & 0.992 & 0.996 & 0.992 \\
\hline & & $p$ & 0.000 & 0.000 & 0.000 & 0.000 \\
\hline & & $D$ & 1.320 & 1.387 & 1.405 & 1.337 \\
\hline & \multirow{2}{*}{$60-160$} & $R^{2}$ & 0.998 & 0.999 & 0.994 & 0.988 \\
\hline & & $p$ & 0.000 & 0.000 & 0.000 & 0.000 \\
\hline
\end{tabular}

Table 6. Fractal dimension of soil temperature in 0-20 cm, 20-60 cm, and 60-100 cm soil layers under different sloping land uses during the 2014 and 2015 growing seasons.

\begin{tabular}{|c|c|c|c|c|c|c|}
\hline \multirow{2}{*}{$\begin{array}{l}\text { Experimental } \\
\text { Year }\end{array}$} & \multirow{2}{*}{$\begin{array}{l}\text { Soil Layer } \\
\text { (cm) }\end{array}$} & \multirow{2}{*}{$\begin{array}{c}\text { Fractal } \\
\text { Dimension }\end{array}$} & \multicolumn{4}{|c|}{ Sloping Land Use } \\
\hline & & & $\begin{array}{c}\text { Soybean } \\
\text { Sloping Field }\end{array}$ & $\begin{array}{c}\text { Maize } \\
\text { Terraced Field }\end{array}$ & $\begin{array}{l}\text { Jujube } \\
\text { Orchard }\end{array}$ & Grassland \\
\hline \multirow{9}{*}{2014} & \multirow{4}{*}{$0-20$} & $D$ & 1.516 & 1.499 & 1.563 & 1.544 \\
\hline & & $R^{2}$ & 0.999 & 0.999 & 0.998 & 0.999 \\
\hline & & $p$ & 0.000 & 0.000 & 0.000 & 0.000 \\
\hline & & $D$ & 1.461 & 1.425 & 1.488 & 1.433 \\
\hline & \multirow[t]{2}{*}{$20-60$} & $R^{2}$ & 0.999 & 0.998 & 1.000 & 0.999 \\
\hline & & $p$ & 0.000 & 0.000 & 0.000 & 0.000 \\
\hline & \multirow{3}{*}{$60-100$} & $D$ & 1.302 & 1.230 & 1.371 & 1.308 \\
\hline & & $R^{2}$ & 0.997 & 0.990 & 0.998 & 0.996 \\
\hline & & $p$ & 0.000 & 0.000 & 0.000 & 0.000 \\
\hline \multirow{9}{*}{2015} & \multirow{4}{*}{$0-20$} & $D$ & 1.568 & 1.486 & 1.574 & 1.553 \\
\hline & & $R^{2}$ & 0.999 & 0.999 & 0.998 & 0.999 \\
\hline & & $p$ & 0.000 & 0.000 & 0.000 & 0.000 \\
\hline & & $D$ & 1.447 & 1.363 & 1.448 & 1.417 \\
\hline & \multirow[t]{3}{*}{$20-60$} & $R^{2}$ & 0.997 & 0.996 & 0.998 & 0.997 \\
\hline & & $p$ & 0.000 & 0.000 & 0.000 & 0.000 \\
\hline & & $D$ & 1.247 & 1.246 & 1.282 & 1.247 \\
\hline & \multirow{2}{*}{$60-100$} & $R^{2}$ & 0.997 & 0.994 & 0.997 & 0.996 \\
\hline & & $p$ & 0.000 & 0.000 & 0.000 & 0.000 \\
\hline
\end{tabular}

In the same soil layer, the complexity of soil moisture varied with different sloping land uses (Table 5). In the 2014 growing season, taking the $0-20 \mathrm{~cm}$ soil layer with the most severe soil moisture change as an example, the fractal dimension of soil moisture in soybean sloping field, maize terraced field, jujube orchard, and grassland was 1.497, 1.489, 1.507, and 1.495, respectively. It can be seen that the fractal dimension of soil moisture in $0-20 \mathrm{~cm}$ soil layer of jujube orchard was the highest, the fractal dimension of soybean sloping field was slightly higher than that of grassland, and the fractal dimension of maize terraced field was relatively low. The fractal dimension of soil moisture in $20-60 \mathrm{~cm}$ and $60-160 \mathrm{~cm}$ soil layers also showed similar patterns. In the 2015 growing season, 
the fractal dimension of soil moisture in the $0-20 \mathrm{~cm}$ and $20-60 \mathrm{~cm}$ soil layers was the highest in the jujube orchard, followed by the soybean sloping field and the lowest in the maize terraced field. In the $60-160 \mathrm{~cm}$ soil layer, the fractal dimension of soil moisture in jujube orchard was still higher than that of the other three sloping land uses.

In the 2014 growing season, the fractal dimension of soil temperature in 0-20 cm soil layer of jujube orchard (1.563) was the highest, followed by grassland, and the lowest in maize terraced field, which was less than 1.5 (Table 6). The fractal dimension of soil temperature in 20-60 cm and 60-100 cm soil layers in jujube orchard was the highest, and the fractal dimension in soybean sloping field was higher than that in grassland, while it was relatively low in maize terraced field. In the 2015 growing season, the fractal dimension of soil temperature in the $0-20 \mathrm{~cm}$ and $20-60 \mathrm{~cm}$ soil layers of jujube orchard was the highest, followed by soybean sloping field and the lowest in maize terraced field. For $60-100 \mathrm{~cm}$ soil layer, the fractal dimension of soil temperature in jujube orchard was relatively high, and there was no significant difference in the fractal dimension of soybean sloping field, maize terraced field, and grassland. The above results show that both in normal precipitation and drought growing seasons, the changes in soil moisture and temperature in jujube orchard were complex and intense, soybean sloping field and grassland relatively reduced the complexity of soil moisture and temperature changes compared to jujube orchard. Maize terraced field minimized the complex changes in soil moisture and temperature in two experimental years.

\section{Discussion}

\subsection{Soil Moisture Change Characteristics}

In most parts of the Loess Plateau, due to the deep soil layer, groundwater generally does not participate in the soil water cycle, precipitation is the sole source for soil moisture, and evapotranspiration is the main expenditure item of soil moisture, so precipitation and evapotranspiration jointly affect soil moisture changes [31]. Different sloping land uses will lead to differences in precipitation interception, infiltration, and evapotranspiration, which will affect the temporal and spatial distribution of soil moisture [32-34].

In this study, it was found that the jujube orchard had the minimum soil moisture content in $0-160 \mathrm{~cm}$ soil layer, with $12.00 \%$ and $9.28 \%$ in the 2014 and 2015 growing seasons, which was significantly lower than other experimental sloping land uses $(p<0.05$; Figure 3$)$. In addition, jujube orchard obtained the maximum soil moisture variation eigenvalue in $0-160 \mathrm{~cm}$ soil layer, with the mean value of $K_{a}$ being 2.049 and 2.389 and the mean value of $C_{v}$ being 0.164 and 0.249 in the 2014 and 2015 growing seasons (Table 3). The reason may be that as a small deciduous tree, the jujube crown is relatively larger than other three plantations (soybean, maize, and grass), which has a prominent interception effect on rainfall, significantly reduces rainfall reaching the ground, thereby reducing soil moisture recharge [35]. On the other hand, the jujube orchard is characterized by large row spacing, small canopy density, and long-term clean tillage, so a large area of soil in the jujube orchard is bare, resulting in strong evaporation and ineffective loss of a large amount of soil moisture [36]. The soil moisture change in jujube orchard is mainly affected by rainfall and evapotranspiration, so soil moisture is susceptible to weather conditions, and frequent dry and wet alternation causes great soil moisture variability.

During the drought growing season, the soil moisture content of $0-160 \mathrm{~cm}$ soil layer in maize terraced field was relatively high (Figure 3). This is mainly because terraced field can intercept and store surface runoff and form a small water storage system, which improves rainfall infiltration and thus increases soil moisture content [37]. It was found that maize terraced field could reduce the variability and active layer of soil moisture (Table 3). This may be due to the fact that the terraced field incorporates part of runoff into the soil during rainfall and converts non-accumulated water infiltration into accumulated water infiltration, which maintains the soil moisture content in a constant range, thus reducing soil moisture fluctuations. 


\subsection{Soil Temperature Change Characteristics}

This study found that soil temperature changes were closely related to air temperature under four experimental sloping land uses (Figure 4). With the increase in soil depth, the influence of air temperature on soil temperature was weakened, and the lag in soil temperature change was more obvious (Figure 4). This may be due to the direct contact between the surface soil and the atmosphere and frequent heat exchange, which makes the soil temperature change greatly. While the upper and lower contact surfaces of the underlying soil are all soil, and the soil itself is a poor conductor of heat, making the heat conduction relatively slow [38]. Therefore, with the deepening of the soil, the change of soil temperature tends to be gentle. The response of soil temperature to air temperature is largely influenced by climate, soil type, vegetation, and topography $[39,40]$. The main reasons for the difference in soil temperature response to air temperature under four sloping land uses are as follows: different sloping land uses not only determine the surface coverage and received solar radiation, but also have a strong impact on the near-surface micro-meteorological environment (humidity, air temperature, etc.) and soil moisture distribution, especially the difference in soil moisture distribution, will inevitably lead to differences in soil heat distribution.

As one of the important indicators of plant growth environment, soil temperature should not be too high or too low. Appropriate soil temperature is conducive to plant growth, otherwise it will have an adverse effect [41]. For an ecosystem, the stability of soil temperature is more conducive to the vegetation growth. The study found that maize terraced field weakened the variability in soil temperature during the growing season (Table 4), which was not only beneficial to the growth of vegetation roots, but also played an important role in the transformation of soil microbial activity and material energy. This may be because the terraced field has a good water retention capacity due to its topographical advantages, which increases the soil moisture content, and the specific heat capacity of water $\left(4.2 \times 10^{3} \mathrm{~J} /\left(\mathrm{kg} \cdot{ }^{\circ} \mathrm{C}\right)\right)$ is much higher than that of soil particles $\left(1.0 \times 10^{3}-2.5 \times 10^{3} \mathrm{~J} /\left(\mathrm{kg} \cdot{ }^{\circ} \mathrm{C}\right)\right)$, which means that the temperature increase in soil particles is higher than that of water when the same amount of heat is absorbed. Conversely, the temperature of soil particles drops faster than water when the same amount of heat is lost during the cooling process. Therefore, for the determined soil, the specific heat capacity increases with increasing moisture content [42]. The higher the moisture content is, the slower the temperature rises and falls, so the terraced field can regulate and stabilize the soil temperature. In the 2014 and 2015 growing seasons, the soil temperature variability in jujube orchard was great (Table 4). The reason for this may be that the surface of jujube orchard is bare and the vegetation coverage is low, which makes the soil temperature susceptible to weather conditions. In addition, the soil moisture content in jujube orchard was low (Figure 3), resulting in a small soil-specific heat capacity and a weak regulation of soil temperature. Therefore, the soil temperature in jujube orchard fluctuated greatly.

\subsection{Application of Wavelet Fractal Method in Analysis of Soil Moisture and Temperature Characteristics}

The soil moisture and temperature change process is a typical nonlinear composite system, which has both deterministic and random characteristics. Soil moisture and temperature changes show periodic changes within a certain period due to the influence of deterministic factors, which can be considered to have statistical self-similarity in fractal theory. Studies have shown that this self-similarity exists in the soil moisture and temperature change process $[22,43,44]$. Therefore, fractal theory can be used to study complex soil moisture and temperature changes. Fractal has two important features: self-similarity and scale invariance. Generally, the fractal dimension can be used to describe the fractal characteristics [45]. In a soil moisture and temperature series, the fractal dimension reflects the temporal and spatial distribution of soil moisture and temperature, and characterizes the complexity and irregularity of soil moisture and temperature. Wavelet analysis has the function of time-frequency multi-resolution and is known as "mathematical microscope". The wavelet transform between large scale and small scale has statistical self-similarity, which can be used to extract spectrum index conveniently, and then to calculate the fractal dimension [45]. 
In this study, the fractal dimension of soil moisture and temperature under four typical sloping land uses in the loess hilly region in the 2014 and 2015 growing seasons was calculated by wavelet fractal dimension method, and the complexity of soil moisture and temperature series under different sloping land uses was evaluated. The results show that regardless of rainfall in the growing season, the fractal dimension of soil moisture and temperature series in maize terraced field was small, and the complexity of soil moisture and temperature changes was low, indicating that terraced field was beneficial to maintaining soil moisture and temperature stability (Tables 5 and 6 ). In the two experimental growing seasons, the fractal dimension of the soil moisture and temperature series of the jujube orchard was the highest, indicating that the change process was the most complicated (Tables 5 and 6). In summary, the complexity of soil moisture and temperature series based on wavelet transform and fractal theory is consistent with that of traditional statistical analysis, which shows that the wavelet fractal dimension method is stable and reliable, and can theoretically verify the complexity of soil moisture and temperature changes in growing season under different sloping land uses, and further indicates that the sloping land use in the loess hilly region has a significant impact on soil moisture and temperature dynamics.

\subsection{Suggestions for Sloping Land Use Improvement}

Water shortage and soil erosion have always been two major problems that plagued the development of the loess hilly region, which not only causes the deterioration of the ecological environment and the decline in land productivity, but also greatly restricts the coordinated development of the local economy, society, and environment. A large number of studies have shown that the over-exploitation and unreasonable utilization of land resources by human beings are the important driving factors for the deterioration of soil and water loss in the loess hilly region, and the sloping field has become the main source for soil and water loss [46,47]. Therefore, in order to control the soil erosion in the loess hilly region, it is necessary to adjust the existing sloping land use.

In view of the fact that terraced field is conducive to maintaining soil moisture and regulating soil temperature, and can provide good soil hydrothermal conditions for plant growth, this study suggests that in the loess hilly region where water resources are scarce and the air temperature difference between daytime and night is large, the sloping field can be converted into terraced field to store rainwater and increase infiltration by intercepting surface runoff. At the same time, soil temperature can also be adjusted by soil moisture, thereby alleviating the damage caused by drastic changes in soil temperature to crops. Aiming at the long-standing problem of water shortage and soil temperature fluctuation in the jujube orchard in the loess hilly region, on the one hand, soil and water conservation engineering measures such as horizontal terraces, fish scale pits and intercepting ditch can be artificially constructed in the jujube orchard [48,49]. By changing the underlying surface to intercept surface runoff, the effective supply for soil moisture is increased, and soil temperature is regulated by soil moisture at the same time. On the other hand, surface mulching is an effective dry farming technique, the most obvious effect of which is soil moisture conservation and soil temperature regulation. According to the existing studies on mulching measures in jujube orchards, straw mulching and jujube branch mulching have strong water-holding capacity and good temperature-regulating effect, which can ensure the appropriate soil temperature for jujube root $[36,50]$. At the same time, crop straw and pruned jujube branches can be utilized in situ, which can save the cost of cover and reduce the pollution of straw burning. It has a certain application value for the simultaneous improvement of economic benefits and ecological functions of dry farming jujube orchards in the loess hilly region. In addition, it can also control the jujube canopy and reduce the leaf area by pruning, which can reduce the transpiration water consumption of jujube trees, is conducive to the preservation of soil moisture, and achieves the purpose of regulating soil temperature by soil moisture [51]. Therefore, it is necessary to vigorously promote water-saving pruning technique in dry farming jujube orchards to maintain the sustainable development of jujube orchards. 


\section{Conclusions}

In this study, the traditional statistical analysis method and wavelet fractal dimension method were combined to analyze the characteristics of soil moisture and temperature changes in the profile under soybean sloping field, maize terraced field, jujube orchard, and grassland in the loess hilly region both in the normal precipitation and drought growing seasons. The main conclusions are as follows:

(1) The jujube orchard obtained the minimum soil moisture content and increased the $K_{a}, C_{v}$, and active layer of soil moisture in $0-160 \mathrm{~cm}$ soil layer both in normal precipitation and drought growing seasons. The jujube orchard also obtained the maximum soil temperature and increased the $K_{a}$ and $C_{v}$ of soil temperature in $0-100 \mathrm{~cm}$ soil layer. Compared with the jujube orchard, soybean sloping field and grassland relatively increased soil moisture content and reduced the $K_{a}$ and $C_{v}$ of soil moisture and soil temperature. Maize terraced field showed the outstanding effect of soil moisture conservation in drought growing season. Maize terraced field reduced the $K_{a}, C_{v}$, and active layer of soil moisture, and kept the stability of soil moisture. Maize terraced field also reduced the $K_{a}$ and $C_{v}$ of soil temperature, which was conducive to regulating soil temperature;

(2) The complexity of soil moisture and temperature changes gradually weakened with the soil layer deepening under the four experimental sloping land uses. The jujube orchard obtained the maximum fractal dimension of soil moisture in the $0-160 \mathrm{~cm}$ soil layer, and also obtained the maximum fractal dimension of soil temperature in the $0-100 \mathrm{~cm}$ soil layer, indicating that the changes in soil moisture and temperature in jujube orchard were the most complex and dramatic both in normal precipitation and drought growing seasons. The fractal dimensions of soil moisture and temperature in soybean sloping field and grassland were lower than jujube orchard, indicating that soybean sloping field and grassland weakened the complexity of soil moisture and temperature changes. Maize terraced field had the minimum fractal dimensions of soil moisture and temperature in two experimental years, indicating that maize terraced field minimized the complexity of soil moisture and temperature changes. The analysis results of the complexity of soil moisture and temperature changes under the experimental sloping land uses based on the wavelet fractal dimension method were basically consistent with the traditional statistical analysis results, indicating that the wavelet fractal dimension method was feasible, which could be used to evaluate the complexity of soil moisture and temperature changes under the typical sloping land uses in the loess hilly region.

In conclusion, it is suggested that the sloping field can be converted into terraced field to achieve the purpose of water storage and soil temperature regulation in the loess hilly region. In order to prevent the jujube orchard from yield reduction or even degradation due to drought and severe soil temperature fluctuation, human management measures such as soil and water conservation engineering measures, mulching, and water-saving pruning technique need to be applied to achieve soil moisture conservation and soil temperature regulation, so as to ensure the sustainable production of jujube orchard. The above results can provide theoretical basis and scientific support for the optimization of sloping land use structure and efficient and sustainable utilization of sloping land resources in the loess hilly region and other arid and semi-arid areas.

Author Contributions: Conceptualization, M.T., X.Z., and P.W.; Methodology, M.T.; Software, C.Z.; Formal Analysis, M.T.; Investigation, M.T.; Data Curation, M.T.; Writing-Original Draft Preparation, M.T.; Writing-Review and Editing, X.G.; Visualization, M.T.; Supervision, X.Z. and P.W.; Project Administration, X.G.; Funding Acquisition, C.Z., X.Z., and P.W. All authors have read and agreed to the published version of the manuscript.

Funding: This work was funded by the National Natural Science Foundation of China (51909228, 51579212, and 41571506), and the National Key Research and Development Program of China (2016YFC0400204).

Acknowledgments: The authors are grateful to Hongchen Li, Lusheng Li, and Qiang Ling for their kind help in conducting the experiment.

Conflicts of Interest: The authors declare no conflict of interest. 


\section{References}

1. Sabri, N.S.A.; Zakaria, Z.; Mohamad, S.E.; Jaafar, A.B.; Hara, H. Importance of soil temperature for the growth of temperate crops under a tropical climate and functional role of soil microbial diversity. Microbes Environ. 2018, 33, 144-150. [CrossRef] [PubMed]

2. Wang, Z.; Xu, W.; Chen, Z.; Jia, Z.; Huang, J.; Wen, Z.; Chen, Y.; Xu, B. Soil moisture availability at early growth stages strongly affected root growth of Bothriochloa ischaemum when mixed with Lespedeza davurica. Front. Plant Sci. 2018, 9, 1050. [CrossRef] [PubMed]

3. Carloto, B.; Buriol, G.; Dornelles, S.; Trivisiol, V.; Peripolli, M.; Escobar, O. Morphological and phenological responses of Eragrostis plana Nees and Eragrostis pilosa (L.) P. Beauv. plants subjected to different soil moisture conditions. Planta Daninha 2019, 37. [CrossRef]

4. Li, G.; Zhao, B.; Dong, S.; Zhang, J.; Liu, P.; Ren, B.; Lu, D.; Lu, W. Morphological and physiological characteristics of maize roots in response to controlled-release urea under different soil moisture conditions. Agron. J. 2019, 111, 1849-1864. [CrossRef]

5. Yuan, Z.; Fang, C.; Zhang, R.; Li, F.; Javaid, M.M.; Janssens, I.A. Topographic influences on soil properties and aboveground biomass in lucerne-rich vegetation in a semi-arid environment. Geoderma 2019, 344, 137-143. [CrossRef]

6. Jia, Y.; Shao, M. Dynamics of deep soil moisture in response to vegetational restoration on the loess plateau of china. J. Hydrol. 2014, 519, 523-531. [CrossRef]

7. Du, S.; Bai, G.; Yu, J. Soil properties and apricot growth under intercropping and mulching with erect milk vetch in the loess hilly-gully region. Plant Soil 2015, 390, 431-442. [CrossRef]

8. Clarke, S.J.; Lamont, K.; Pan, H.; Barry, L.; Hall, A.; Rogiers, S.Y. Spring root-zone temperature regulates root growth, nutrient uptake and shoot growth dynamics in grapevines. Aust. J. Grape Wine Res. 2015, 21, 479-489. [CrossRef]

9. Kubisch, P.; Leuschner, C.; Coners, H.; Gruber, A.; Hertel, D. Fine root abundance and dynamics of stone pine (Pinus cembra) at the alpine treeline is not impaired by self-shading. Front. Plant Sci. 2017, 8, 602. [CrossRef]

10. Yang, L.; Wei, W.; Chen, L.; Mo, B. Response of deep soil moisture to land use and afforestation in the semi-arid Loess Plateau, China. J. Hydrol. 2012, 475, 111-122. [CrossRef]

11. Li, Q.; Liu, G.; Xu, M.; Sun, H.; Zhang, Z.; Gao, L. Effect of seasonal freeze-thaw on soil anti-scouribility and its related physical property in hilly Loess Plateau. Trans. Chin. Soc. Agric. Eng. 2013, 29, 105-112. (In Chinese)

12. Gao, X.; Wu, P.; Zhao, X.; Wang, J.; Shi, Y. Effects of land use on soil moisture variations in a semi-arid catchment: Implications for land and agricultural water management. Land Degrad. Dev. 2014, 25, 163-172. [CrossRef]

13. Wang, J.; Liu, H.; Wu, X.; Li, C.; Wang, X. Effects of different types of mulches and legumes for the restoration of urban abandoned land in semi-arid northern china. Ecol. Eng. 2017, 102, 55-63. [CrossRef]

14. Niu, C.; Musa, A.; Liu, Y. Analysis of soil moisture condition under different land uses in the arid region of horqin sandy land, northern china. Solid Earth 2015, 6, 1157-1167. [CrossRef]

15. Wang, H.; Xiao, W.; Zhao, Y.; Wang, Y.; Hou, B.; Zhou, Y.; Yang, H.; Zhang, X.; Cui, H. The spatiotemporal variability of evapotranspiration and its response to climate change and land use/land cover change in the three gorges reservoir. Water 2019, 11, 1739. [CrossRef]

16. Kang, S.; Kim, S.; Oh, S.; Lee, D. Predicting spatial and temporal patterns of soil temperature based on topography, surface cover and air temperature. For. Ecol. Manag. 2000, 136, 173-184. [CrossRef]

17. Ma, K.; He, X.; Ma, B.; Luo, D.; Ma, Y. Effects of land use pattern on soil in the loess plateau of south ningxia. Ecol. Environ. 2006, 15, 1231-1236. (In Chinese)

18. Gao, H.; Shao, M. Effect of rainfall on soil water and soil temperature in arid region. J Irrig. Dra 2011, 30, 40-45. (In Chinese)

19. Yu, B.; Liu, G.; Liu, Q.; Wang, X.; Feng, J.; Huang, C. Soil moisture variations at different topographic domains and land use types in the semi-arid loess plateau, china. Catena 2018, 165, 125-132. [CrossRef]

20. Savva, Y.; Szlavecz, K.; Pouyat, R.V.; Groffman, P.M.; Heisler, G. Effects of land use and vegetation cover on soil temperature in an urban ecosystem. Soil Sci. Soc. Am. J. 2010, 74, 469-480. [CrossRef]

21. Mandelbrot, B.B. The Fractal Geometry of Nature; WH freeman New York: New York, NY, USA, 1983; Volume 173. 
22. Fu, Q.; Hou, R.; Wang, Z.; Li, T. Soil moisture thermal interaction effects under snow cover during freezing and thawing period. Trans. Chin. Soc. Agric. Eng. 2015, 31, 101-107. (In Chinese)

23. Luan, Q.; Wu, X.; Gao, X.; Sun, Q.; Li, Y. Analysis on change of precipitation complexity distribution in typical region. Water Resour. Hydropower Eng. 2014, 45, 24-27. (In Chinese)

24. Hao, M.; Wei, X.; Dang, T. Effect of long-term applying zinc fertilizer on wheat yield and content of zinc in dry land. Plant Nutr. Fertil. Sci. 2003, 9, 377-380. (In Chinese)

25. Chen, J.; Zheng, X.; Qin, Z.; Liu, P.; Zang, H.; Sun, M. Effects of maize straw mulch on spatiotemporal variation of soil profile moisture and temperature during freeze-thaw period. Trans. Chin. Soc. Agric. Eng. 2013, 29, 102-110. (In Chinese)

26. Abdi, H. Coefficient of variation. Encycl. Res. Des. 2010, 1, 169-171.

27. Yu, L.; Wei, D.; WANG, H.; Huang, Q.; Peng, Y.; Xu, Y. Spatial variability of soil organic matter and appropriate number of samples on county scale in jianghan plain. J. Nat. Resour. 2016, 31, 855-864. (In Chinese)

28. Sang, Y.; Wang, D.; Wu, J.; Zhu, Q.-P.; Wang, L. Quantitative characterization of complicated characteristics of hydrologic series. J. China Hydrol. 2010, 5, 1-6, 56. (In Chinese)

29. Abry, P.; Veitch, D. Wavelet analysis of long-range-dependent traffic. IEEE Trans. Inf. Theory 1998, 44, 2-15. [CrossRef]

30. Wang, W.; Xiang, H.; Zhao, D. Estimating the fractal dimension of hydrological time series by wavelet analysis. J. Sichuan Univ. (Eng. Sci. Ed.) 2005, 37, 1-4. (In Chinese)

31. Jian, S.; Zhao, C.; Fang, S.; Yu, K. Effects of different vegetation restoration on soil water storage and water balance in the chinese loess plateau. Agric. For. Meteorol. 2015, 206, 85-96. [CrossRef]

32. Macinnis-Ng, C.M.; Flores, E.E.; Müller, H.; Schwendenmann, L. Throughfall and stemflow vary seasonally in different land-use types in a lower montane tropical region of panama. Hydrol. Process. 2014, 28, 2174-2184. [CrossRef]

33. Yang, Y.; Chen, R.; Song, Y.; Han, C.; Liu, J.; Liu, Z. Comparison of precipitation and evapotranspiration of five different land-cover types in the high mountainous region. Sci. Cold Arid Reg. 2018, 9, 534-542.

34. Tang, M.; Zhao, X.; Gao, X.; Zhang, C.; Wu, P.; Li, H.; Ling, Q.; Chau, H. Characteristics of soil moisture variation in different land uses in a small catchment on the loess plateau, china. J. Soil Water Conserv. 2019, 74, 24-32. [CrossRef]

35. Tao, Z.; Si, B.; Jin, J. Canopy interception modified intra-rainfall isotopic and hydrochemical characteristics of dwarfed jujube tree. J. Soil Water Conserv. 2017, 31, 189-195. (In Chinese)

36. Wang, J.; Huang, J.; Zhao, X.; Wu, P.; Horwath, W.R.; Li, H.; Jing, Z.; Chen, X. Simulated study on effects of ground managements on soil water and available nutrients in jujube orchards. Land Degrad. Dev. 2016, 27, 35-42. [CrossRef]

37. Arnáez, J.; Lana-Renault, N.; Lasanta, T.; Ruiz-Flaño, P.; Castroviejo, J. Effects of farming terraces on hydrological and geomorphological processes. A Rev. Catena 2015, 128, 122-134. [CrossRef]

38. Sauer, T.J.; Ochsner, T.E.; Horton, R. Soil heat flux plates. Agron. J. 2007, 99, 304-310. [CrossRef]

39. Zhang, S.; Li, X. Soil moisture and temperature dynamics in typical alpine ecosystems: A continuous multi-depth measurements-based analysis from the qinghai-tibet plateau, china. Hydrol. Res. 2018, 49, 194-209. [CrossRef]

40. Ni, J.; Cheng, Y.; Wang, Q.; Ng, C.W.W.; Garg, A. Effects of vegetation on soil temperature and water content: Field monitoring and numerical modelling. J. Hydrol. 2019, 571, 494-502. [CrossRef]

41. Štraus, I.; Mrak, T.; Ferlan, M.; Železnik, P.; Kraigher, H. Influence of soil temperature on growth traits of European beech seedlings. Can. J. For. Res. 2015, 45, 246-251. [CrossRef]

42. Zhao, Y.; Si, B. Thermal properties of sandy and peat soils under unfrozen and frozen conditions. Soil Tillage Res. 2019, 189, 64-72. [CrossRef]

43. Liao, K.; Lai, X.; Zhou, Z.; Zhu, Q. Applying fractal analysis to detect spatio-temporal variability of soil moisture content on two contrasting land use hillslopes. CATENA 2017, 157, 163-172. [CrossRef]

44. Su, S. Spatial Heterogeneity and Vegetation Maintaining Mechanism of Pinus taiwanensis Forest in Daiyun Mountain High Altitude Area. Ph.D. Thesis, Fujian Agriculture And Forestry University, Fujian, China, 2015.

45. Ai, X.; Dong, Q.; Wang, X.; Zhang, Y. Application of wavelet fractal dimension estimation in dividing flood stages for three gorges reservoir. Syst. Eng. -Theory Pract. 2009, 29, 145-151. [CrossRef]

46. Feng, X.; Wang, Y.; Chen, L.; Fu, B.; Bai, G. Modeling soil erosion and its response to land-use change in hilly catchments of the chinese loess plateau. Geomorphology 2010, 118, 239-248. [CrossRef] 
47. Zhao, G.; Mu, X.; Wen, Z.; Wang, F.; Gao, P. Soil erosion, conservation, and eco-environment changes in the loess plateau of china. Land Degrad. Dev. 2013, 24, 499-510. [CrossRef]

48. Liang, K.; Qi, J.; Liu, E.; Jiang, Y.; Li, S.; Meng, F. Estimated potential impacts of soil and water conservation terraces on potato yields under different climate conditions. J. Soil Water Conserv. 2019, 74, 225-234. [CrossRef]

49. Huo, J.; Yu, X.; Liu, C.; Chen, L.; Zheng, W.; Yang, Y.; Tang, Z. Effects of soil and water conservation management and rainfall types on runoff and soil loss in sloped area in north china. Land Degrad. Dev. 2020. [CrossRef]

50. Li, H.; Zhao, X.; Gao, X.; Ren, K.; Wu, P. Effects of water collection and mulching combinations on water infiltration and consumption in a semiarid rainfed orchard. J. Hydrol. 2018, 558, 432-441. [CrossRef]

51. Ma, L.; Wang, X.; Gao, Z.; Youke, W.; Nie, Z.; Liu, X. Canopy pruning as a strategy for saving water in a dry land jujube plantation in a loess hilly region of china. Agric. Water Manag. 2019, 216, 436-443. [CrossRef]

(C) 2020 by the authors. Licensee MDPI, Basel, Switzerland. This article is an open access article distributed under the terms and conditions of the Creative Commons Attribution (CC BY) license (http://creativecommons.org/licenses/by/4.0/). 